\title{
Comparison of the effect of Kalsitrapine and metformin as adjunctive therapy in the treatment of infertility in women with polycystic ovary syndrome
}

\author{
Faranak Jalilvand $^{1}$, Shahla Farzipour ${ }^{1}$, Firouz Amani², Sousan Hooshmandi ${ }^{3 *}$, Sajjad Naeimi ${ }^{4}$
}

${ }^{1}$ Department of Obstetrics and Gynecology, ${ }^{2}$ Department of Community Medicine, ${ }^{3}$ Department of Midwifery, ${ }^{4}$ Faculty of Medicine, Ardabil University of Medical Sciences, Ardabil, Iran

Received: 06 December 2021

Revised: 02 January 2022

Accepted: 03 January 2022

*Correspondence:

Dr. Sousan Hooshmandi,

Email: sousan2020@gmail.com

Copyright: (c) the author(s), publisher and licensee Medip Academy. This is an open-access article distributed under the terms of the Creative Commons Attribution Non-Commercial License, which permits unrestricted non-commercial use, distribution, and reproduction in any medium, provided the original work is properly cited.

\begin{abstract}
Background: Chronic anovulation is one of the most common causes of infertility. In women with polycystic ovary syndrome (PCOS), other factors related to oocyte quality or endometrial and nesting disorders may also play a role. Infertile and non-ovulatory women who tend to become pregnant are candidates for ovulation induction. The aim of this study was to evaluate the effect of Kalsitrapine and metformin on the treatment of patients with PCOS.

Methods: The clinical trial study was performed on 80 female patients with PCOS who had referred to Ardabil city hospital for infertility treatment were randomly divided in two groups with personal consent. One group received Kalsitrapine and another group received metformin.

Results: The mean age of all patients was 26.08 \pm 5.21 . There was no significant difference between 2 groups in term of age and BMI. There was no statistically significant difference between the two groups in terms of primary and secondary infertility. The mean duration of infertility was $3.68 \pm 3.49$ years. There was no statistically significant difference between the 2 groups in terms of infertility duration. There was no statistically significant difference between the 2 groups in terms of the type of menstrual cycle. The response rate to treatment was $17.5 \%$ in the metformin group and $10 \%$ in the Kalsitrapine group. There was no statistically significant difference between the 2 groups in terms of response to treatment. In comparison, none of the studied factors in the 2 groups was significantly associated with the response to treatment.

Conclusions: It is true that the recovery rate of the herbal medicine Kalcitropine in this study was slightly lower than metformin, but due to the side effects of metformin, including lethargy, abdominal pain, diarrhea, headache, constipation, bloating, weight loss, heartburn, nausea and Vomiting, unpleasant taste of metal in the mouth In some people, such people may be prescribed kalcitrapine for a longer period of time to evaluate its effect.
\end{abstract}

Keywords: Kalsitrapine, Metformin, Infertility, Women, PCOS

\section{INTRODUCTION}

In 1935 Irving F. Stein and Michael L. Leventhal first described a complex of symptoms associated with anovulation. Acceptance of PCOS as a distinct clinical nature has led to the problem being evaluated in a more difficult way over the years. Only women with this syndrome were known to have a history of oligo amenorrhea, Hirsutism and obesity with large polycystic ovaries, which are now known to be very severe cases. 
Clinically, this problem should be considered as a problem of persistent ovulation with a range of etiology and clinical manifestations (including insulin resistance, hyperinsulinemia and hyperandrogenism). ${ }^{1-7}$

The most common clinical symptom in patients with polycystic ovaries is hirsutism, which is seen in approximately $70 \%$ of patients and in areas such as Japan, this symptom is seen in $10-20 \%$ of patients, which may be due to genetic differences in the activity of the enzyme 5-alpha reductase..$^{8-11}$ About $50 \%$ of patients with amenorrhea present with oligo amenorrhea and about $30 \%$ of patients with irregular or heavy bleeding (menometrorazhi). Another symptom of these patients is obesity, but due to the fact that chronic non ovulation has different causes, the presence of obesity is of little value. Infertility is also one of the most common complaints of these patients and chronic lack of ovulation is the cause of $30 \%$ of infertility and among these, PCOS is the most common cause. ${ }^{12-14}$

Macroscopically, PCOS ovaries are 2 to 5 times their normal size. Their cross-sectional area shows a white cortex that has numerous cysts and is typically less than 1 $\mathrm{cm}$ in diameter. Microscopically, the superficial cortex is fibrous and small and may have prominent blood vessels. $^{13-15}$

Chronic ovulation is one of the most common causes of infertility. In women with PCOS, other factors related to oocyte quality or endometrial and nesting disorders may also play a role. Infertile and infertile women who tend to become pregnant are candidates for the ovulation induction. ${ }^{15-18}$

Various studies around the world have measured the effects of different drugs on PCO with different results. ${ }^{5,19,20}$ Infertile and infertile women who tend to become pregnant are candidates for ovulation induction, this study seems to be necessary in order to be able to decide whether or not to use Kalsitrapine. It should be noted that so, far no reliable study has been conducted on the herbal drug Kalsitrapine and its effect in the treatment of infertility in women with polycystic ovary syndrome, both in Iran and in the world. The aim of this clinical trial was to evaluate the effect of Kalsitrapine and metformin on the treatment of infertility in the patients with the PCOS.

\section{METHODS}

\section{Study design}

The present study was a clinical trial from October 2019 to September 2020 in Ardabil city hospital on 80 patients with PCOS who were randomly selected and entered into the study with personal consent. The person in charge of following up the study and following up the patients in order to prescribe the drugs and the result of the treatment was the clinic technician. Initially, a checklist containing patients' demographic information including height, weight, history of smoking and alcohol consumption, level of education, occupation and medical history was completed for all patients.

\section{Participants and measurements}

Patients were evaluated for symptoms related to PCOS such as abdominal pain and menstrual irregularities. The patients were then randomly divided into 2 equal groups (40 patients). The first group (case) received the herbal medicine Kalsitrapine and the second group (control) also, received a metformin containing treatment regimen. The duration of treatment of patients in both groups was 3 months. After three months, patients were evaluated for response to treatment. In the metformin group, metformin $500 \mathrm{mg}$ tablets were used for the twice daily for the three months.

In the Kalsitrapine group, 3 gm sachet was used twice a day for 3 months. Because the minimum time required to effect ovulation and insulin metabolism is 1.5 months, the duration of treatment was 3 months. The response to treatment in the present study was to evaluate the pregnancy rate, which was measured based on the betahCG level and then ultrasound. Three of those taking Kalsitrapine were excluded from the study due to nausea and were given a replacement. In this study, women aged 20-45 years had no oligo amenorrhea or menstrual disorders, no clinical signs of hyperandrogenism and no history of drug use for menstrual disorders in the last three months and there was no male factor in their spouse and they also entered the study without a history of neurological diseases and women under 20 and over 45 with a history of medication for menstrual disorders as well as a history of mental illness, oligo amenorrhea or menstrual disorders, clinical signs of hyperandrogenism and no history of medication for menstrual disorders in the last three months with a male factor in their husband, excluded from the study.

\section{Ethical approval}

This study was registered in the ethics committee of the University of Medical Sciences with the code IR.ARUMS.REC.1397.142 and in the clinical trial center of Iran with the code IRCT: IRCT20140422017388N3. Written consent was obtained from all patients before the study.

\section{Statistical analysis}

Data were analyzed in SPSS 22 using descriptive statistics methods in the form of tables, graphs and analytical statistics methods using $\mathrm{t}$ test, chi-square and logistic regression for quantitative and qualitative data. Significance level less than 0.05 was considered significant. 


\section{RESULTS}

The mean age of all patients was $26.08 \pm 5.21$. There was no significant difference between two groups in term of age and BMI (Table 1).

Table 1: BMI distribution of patients.

\begin{tabular}{|c|c|c|c|c|c|}
\hline \multirow{2}{*}{$\begin{array}{l}\text { BMI } \\
\left(\mathrm{Kg} / \mathrm{m}^{2}\right)\end{array}$} & \multicolumn{2}{|c|}{$\begin{array}{l}\text { Metformin } \\
\text { group }\end{array}$} & \multicolumn{2}{|c|}{$\begin{array}{l}\text { Kalsitrapine } \\
\text { group }\end{array}$} & \multirow{2}{*}{$\begin{array}{l}P \\
\text { value }\end{array}$} \\
\hline & $\mathbf{N}$ & $\%$ & $\mathbf{N}$ & $\%$ & \\
\hline Normal & 7 & 17.5 & 7 & 17.5 & \multirow{4}{*}{0.54} \\
\hline Overweight & 15 & 37.5 & 16 & 40 & \\
\hline Obesity & 18 & 45 & 17 & 42.5 & \\
\hline Total & 40 & 100 & 40 & 100 & \\
\hline
\end{tabular}

There was no statistically significant difference between the 2 groups in terms of primary and secondary infertility. The average duration of infertility in all patients was $3.3 \pm 68.49$ years. There was no statistically significant difference between the 2 groups in terms of duration of infertility. There was no statistically significant difference between 2 groups in terms of the type of menstrual cycle. The response rate to treatment was $17.5 \%$ in the metformin group and $10 \%$ in the Kalsitrapine group. There was no statistically significant difference between the two groups in terms of response to treatment (Table 2).

Table 2: Response to treatment between the 2 study groups.

\begin{tabular}{|lllllll|} 
Response to & \multicolumn{2}{l}{ Positive } & \multicolumn{2}{c}{ Negative } & P \\
group therapy & $\mathbf{N}$ & $\boldsymbol{\%}$ & $\mathbf{N}$ & $\%$ & value \\
\hline Metformin & 7 & 17.5 & 33 & 82.5 & \\
\cline { 1 - 5 } Calcitrapin & 4 & 10 & 36 & 90 & 0.259 \\
\cline { 1 - 5 } Total & 11 & 13.8 & 69 & 86.3 & \\
\hline
\end{tabular}

\section{DISCUSSION}

In the study of Uncle et al entitled comparison of metformin and chrome picolinate in patients with PCOS resistant to clomiphene citrate, 92 people were included in the study. Patients were randomly divided into two groups: One group received 200 micro gm of chrome picolinate daily and the other group received 1,500 milligm of metformin daily for three months. Hormonal and anthropometric characteristics of both groups were measured and compared before and after treatment. Ovulation and pregnancy rates in both groups were also studied. Chrome picolinate clearly reduced fasting blood sugar after three months of treatment. Similarly, serum insulin levels decreased and increased insulin sensitivity measured by the QUICKI index. Levels of testosterone and free testosterone decreased more after three months of treatment in patients receiving metformin than in the chromium group. Ovulation and pregnancy rates were the same in both groups. In our study, the two groups that received metformin or Kalsitrapine were not statistically significantly different, but the success rate in pregnancy was slightly higher in the metformin group than in Kalsitrapine. ${ }^{21}$

Baran et al in Turkey study comparing the effects of metformin and clomiphene citrate on induction of ovulation in 69 pregnant women with PCOS, showed that both of these drugs are used in the first line of treatment to improve pregnancy rates in women with PCOS. ${ }^{22}$ In the present study, $17.5 \%$ of patients in the metformin group were successfully treated, which was significantly more than the study of Baran et al with $8 \%$, reason for this contradictory result can be found in the possible conditions of genetic differences and pharmacogenomics issues of the drug and to resolve this contradiction, it is suggested to conduct a study with the same title with a larger statistical community at the national level. ${ }^{22}$

A study by Azargoon et al comparing pregnant and nonpregnant women with polycystic ovary syndrome resistant to clomiphene citrate combined with metformin and letrozole. In this descriptive cross-sectional study, 106 patients with clomiphene citrate resistant PCOS referred to the infertility clinic of Amir Al-Mo'menin hospital in Semnan during 2005-2008 were studied. ${ }^{23}$ All patients were given metformin at a dose of $1500 \mathrm{mg}$ daily $(500 \mathrm{mg}$ 3 times daily) for 6 to 8 weeks and then treated with letrozole at a daily dose of $2.5 \mathrm{mg}$ from day 3 to 7 of the menstrual cycle they got. When ovulation did not occur at a dose of $2.5 \mathrm{mg}$ letrozole, the dose of letrozole was increased to 5 and then $7.5 \mathrm{mg}$ in subsequent cycles. Out of 106 patients treated with metformin, 1 was excluded from the study due to drug allergy in the form of rash after taking metformin. Out of 105 patients, 14 patients $(13.33 \%)$ became pregnant with metformin alone. Of the remaining 91 patients who entered letrozole treatment with metformin, $83(91.2 \%)$ ovulated by the end. In total, the pregnancy rate at the end of the study was 60 per 105 $(57.14 \%)$. Of these 60 pregnancies, $10(16.7 \%)$ had abortions, $5(8.3 \%)$ preterm deliveries and $45(74.9 \%)$ term deliveries. The results showed that there was a significant difference between pregnant and non-pregnant women during infertility, BMI, LH, FSH and LH/FSH ratio, $\mathrm{PCO}$ image on ultrasound in one or both ovaries, meniscus (oligo amenorrhea, amenorrhea) and hirsutism. The only significant difference was that pregnant women were younger than non-pregnant women. In our study, the effectiveness of metformin was $17.5 \%$, which was slightly higher than Azargoon et al. ${ }^{23}$ Also, the amount of treatment with Kalsitrapine was almost equal to that of metformin comparing the findings and the fact that Kalsitrapine is an herbal medicine with fewer side effects suggests that the combination of Kalsitrapine and letrozole is likely to provide a better response with fewer side effects in these patients and the need for this study seems necessary. 


\section{CONCLUSION}

It is true that the recovery rate of the herbal medicine kalcitropine in this study was slightly lower than metformin, but due to the side effects of metformin, including lethargy, abdominal pain, diarrhea, headache, constipation, bloating, weight loss, heartburn, nausea and vomiting, unpleasant taste of metal in the mouth In some people, such people may be prescribed kalcitrapine for a longer period of time to evaluate its effect. It is recommended that in the other studies the use of kalcitrapine evaluated in the long-time duration of treatment.

\section{ACKNOWLEDGEMENT}

Authors would like to thanks Tabriz Hakim Razi Azar company (MersPharma) to financially supported of this research.

Funding: No funding sources Conflict of interest: None declared

Ethical approval: The study was approved by the Institutional Ethics Committee

\section{REFERENCES}

1. McCartney CR, Marshall JC. Polycystic Ovary Syndrome. N Engl J Med. 2016;375(1):54-64.

2. Arentz S, Smith CA, Abbott J, Fahey P, Cheema BS, Bensoussan A. Combined lifestyle and herbal medicine in overweight women with polycystic ovary syndrome (PCOS): A randomized controlled trial. Phytotherapy Res. 2017;31(9):1330-40.

3. Teng B, Peng J, Ong M, Qu X. Successful Pregnancy after Treatment with Chinese Herbal Medicine in a 43-Year-Old Woman with Diminished Ovarian Reserve and Multiple Uterus Fibrosis: A Case Report. Medicines. 2017;4(1):7.

4. Lai L, Flower A, Moore M, Lewith G. Chinese herbal medicine and polycystic ovary syndrome: A randomized feasibility and pilot study in the United Kingdom. J Alternative Complementary Med. 2014;20(5):61-2.

5. Shayan A, Masoumi SZ, Shobeiri F, Tohidi S, Khalili A. Comparing the Effects of Agnugol and Metformin on Oligomenorrhea in Patients with Polycystic Ovary Syndrome: A Randomized Clinical Trial. J Clin Diagnostic Res. 2016;10(12):13.

6. Sirmans SM, Pate KA. Epidemiology, diagnosis, and management of polycystic ovary syndrome. Clin Epidemiol. 2013;6(1):1-13.

7. Badawy A, Elnashar A. Treatment options for polycystic ovary syndrome. Int J Women's Health. 2011;12(3):25-35.

8. Kashani L, Akhondzadeh S. Herbal Medicine in the Treatment of Polycystic Ovary Syndrome. Herbal Med J. 2016;3(59):1-5.
9. Nandi A, Chen Z, Patel R, Poretsky L. Polycystic ovary syndrome. Endocrinol Metabol Clin North Am. 2014;43(5):123-47.

10. Lai L, Flower A, Prescott P, Moore M, Lewith G. Chinese herbal medicine for oligomenorrhoea and amenorrhoea in polycystic ovary syndrome: A 4 randomized feasibility study in the United Kingdom. Integrative Med Res. 2015;4(1):15.

11. Arentz S, Abbott JA, Smith CA, Bensoussan A. Herbal medicine for the management of polycystic ovary syndrome (PCOS) and associated oligo/amenorrhoea and hyperandrogenism; a review of the laboratory evidence for effects with corroborative clinical findings. BMC Complementary Alternative Med. 2014;14(1):511.

12. Kamalanathan S, Sahoo JP, Sathyapalan T. Pregnancy in polycystic ovary syndrome. Indian $\mathrm{J}$ Endocrinol Metab. 2013;17(1):37-43.

13. Lashen H. Review: Role of metformin in the management of polycystic ovary syndrome. Therapeutic Advances in Endocrinology and Metabolism. 2010;12(1):117-28.

14. Roe AH, Dokras A. The diagnosis of polycystic ovary syndrome in adolescents. Rev Obstet Gynecol. 2011;4(2):45-51.

15. Pauli JM, Raja-Khan N, Wu X, Legro RS. Current perspectives of insulin resistance and polycystic ovary syndrome. Diabet Med. 2011;28(12):1445-54.

16. Lai L, Flower A, Moore M, Prescott P, Lewith G. Polycystic ovary syndrome: a 4 randomized feasibility and pilot study using Chinese Herbal medicine to explore Impact on Dysfunction (ORCHID)- study protocol. Eur J Integrative Med. 2014;6(3):392-9.

17. Goswami PK, Khale A, Ogale S. Natural remedies for polycystic ovarian syndrome (PCOS): a review. Int J Pharmaceutical Phytopharmacological Res. 2017;1(6):396-402.

18. Wu XK, Wang YY, Liu JP, Hou LH, Gao YQ, Du SM et al. Letrozole, berberine, or a combination for infertility in Chinese women with polycystic ovary syndrome: a 4 randomized, double-blind, placebocontrolled trial. Lancet. 2015;31(386):70.

19. Yilmaz M, Karakoc A. The effects of rosiglitazone and metformin on menstrual cyclicity and hirsutism in polycystic ovary syndrome. Gynecol Endocrinol. 2015;21(3):154-60.

20. Krstevska B, Dimitrovski CH. Metformin improves menstrual patterns, endocrine and metabolic profile in obese hyperinsulinemic women with a polycystic ovary syndrome. Prilozi. 2016;27(1):57-66.

21. Amooee S, Parsanezhad ME, Ravanbod Shirazi M, Alborzi S, Samsami A. Metformin versus chromium picolinate in clomiphene citrate-resistant patients with PCOS: A double-blind randomized clinical trial. IJRMS. 2013;11(8):611.

22. Baran S, Api M, Goksedef BP, Cetin A. Comparison of metformin and clomiphene citrate therapy for induction of ovulation in the polycystic ovary 
syndrome. Arch Gynecol Obstet. 2010;282(4):43943.

23. Azargoon A, Alavi Toussy J. Comparison of pregnant and non-pregnant women with clomiphene resistant polycystic ovary syndrome in treatment with metformin and letrozole. Koomesh. 2011;12(3):32733.
Cite this article as: Jalilvand F, Farzipour S, Amani F, Hooshmandi S, Naeimi S. Comparison of the effect of Kalsitrapine and metformin as adjunctive therapy in the treatment of infertility in women with polycystic ovary syndrome. Int J Basic Clin Pharmacol 2022;11:86-90. 